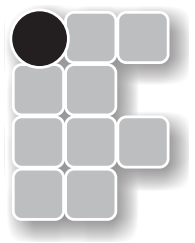

\title{
EFEITO DA SALINIDADE NO CRESCIMENTO INICIAL DO MARACUJAZEIRO AMARELO (PASSIFLORA EDULIS SIMS. F. FLAVICARPA DEG.)
}

Aureliano Albuquerque Ribeiro ${ }^{1}$

Marconi Seabra Filho²

Francisco José Carvalho Moreira ${ }^{3}$

Ademir Silva Menezes ${ }^{4}$

Maria Cristina Barbosa ${ }^{5}$

\section{Resumo}

Objetivou-se, com este estudo, avaliar o efeito de cinco níveis de salinidade da água de irrigação $\left(T_{1}=\right.$ testemunha $=0,27 ; T_{2}=1,5 ; T_{3}=2,5 ; T_{4}=3,5$ e $\left.T_{5}=4,5 \mathrm{dS} / \mathrm{m}^{-1}\right)$ sobre o crescimento inicial do maracujazeiro amarelo. 0 trabalho foi conduzido em condições de laboratório e campo (casa de vegetação), no Instituto Federal de Educação, Ciência e Tecnologia do Ceará - Campus de Sobral. 0 delineamento estatístico adotado foi o inteiramente casualizado (DIC), com quatro repetições, colocando-se 32 sementes por unidade experimental. As variáveis analisadas foram: altura das plantas (AP); número de folhas (NF); diâmetro do caule (DC); massa seca da parte aérea (MSPA) e massa seca da raiz (MSR). 0 maracujazeiro amarelo apresentou elevada sensibilidade aos sais, sendo que, com exceção do diâmetro do caule, as demais variáveis avaliadas foram afetadas de maneira significativa pelo estresse salino a partir de $1,5 \mathrm{dS} / \mathrm{m}^{-1}$.

Palavras-chave: Agricultura. Qualidade da água. Estresse salino.

\section{Introdução}

A salinidade é um problema que atinge cerca de 50 dos 230 milhões de hectares da área irrigada do globo terrestre, trazendo sérios prejuízos para a produção agrícola, principalmente nas regiões áridas e semiáridas, onde cerca de $25 \%$ da área irrigada já se encontra salinizada (FAO, 2000). No Brasil, aproximadamente nove milhões de hectares são afetados pela presença de sais, cobrindo sete estados. A maior área afetada está localizada no estado da Bahia (44\% do total), seguido pelo estado do Ceará, com $25 \%$ da área total do país (GHEYI; FAGERIA, 1997)

A presença de sais de sódio no solo provoca redução generalizada do crescimento das plantas cultivadas, com sérios prejuízos para a atividade agrícola. A redução no crescimento é consequência de respostas fisiológicas, incluindo-se modificações no balanço de íons, potencial hídrico, nutrição mineral, fechamento estomático, eficiência fotossintética e alocação de assimilados (FLOWER et al., 1986; BETHKE; DREW, 1992)

A salinidade na rizosfera acarreta redução na permeabilidade das raízes para a água, dando origem ao estresse hídrico. A componente osmótica resulta das elevadas concentrações de sais dissolvidos na solução do substrato, os quais reduzem o potencial osmótico desta solução e, consequentemente, diminuem a disponibilidade da água para a planta. 0 efeito iônico, por outro lado, refere-se aos íons absorvidos pelas plantas, os quais podem provocar desequilíbrio iônico e/ou efeitos tóxicos para o

\footnotetext{
1Universidade Federal do Piauí - Mestrando em Agronomia:Solos e Nutrição de Plantas - campus professora Cinobelina Elvas. E-mail: aureliano05051991@gmail.com

2Instituto Federal de Educação, Ciência e Tecnologia do Ceará - CAMPUS DE SOBRAL - Professor do Departamento de Recursos Naturais. E-mail: marconi@ifce.edu.br

3Instituto Federal de Educação, Ciência e Tecnologia do Ceará - CAMPUS DE SOBRAL - Professor do Departamento de Recursos Naturais. E-mail: franzecm@gmail.com

${ }^{4}$ Instituto Federal de Educação, Ciência e Tecnologia do Ceará - CAMPUS DE SOBRAL - Graduando do Curso Superior de Tecnologia em Irrigação e Drenagem. E-mail: amenezzes@gmail.com

${ }^{5}$ Instituto Federal de Educação, Ciência e Tecnologia do Ceará - CAMPUS DE SOBRAL - Graduando do Curso Superior de Tecnologia em Irrigação e Drenagem. E-mail: crismariabarbosa@gmail.com
} 
metabolismo da planta (WILLADINO; CÂMARA, 2004). Em consequência, as plantas fecham os estômatos para reduzir a perda de água por transpiração, resultando em uma taxa fotossintética menor, o que constitui uma das causas do reduzido crescimento das espécies sob condições de estresse salino (O'LEARY, 1971).

As plantas cultivadas são classificadas como sensíveis, moderadamente sensíveis, moderadamente tolerantes e tolerantes ou resistentes no que se refere à ação degenerativa dos sais na germinação, crescimento e produção, (BERNISTEIN, 1964; AYERS; WESTCOT, 1999). As sensíveis não germinam, não crescem e nem produzem adequadamente em locais onde a condutividade elétrica do extrato de saturação do solo seja superior a $1,3 \mathrm{dS} / \mathrm{m}^{-1}$, as moderadamente sensíveis, em ambientes com concentração salina $>3 \mathrm{dS} / \mathrm{m}^{-1}$, as moderadamente tolerantes, quando a salinidade for superior a $6 \mathrm{dS} / \mathrm{m}^{-1}$ e as tolerantes ou resistentes quando o teor salino do solo atingir valores acima de $10 \mathrm{dS} / \mathrm{m}^{-1}$. Esses valores de condutividade elétrica do extrato de saturação equivalem às concentrações de sais dissolvidos na solução do solo de 0,$83 ; 1,92 ; 3,84$ e 6,40 $\mathrm{g} \mathrm{L}^{-1}$, respectivamente ( SOUSA et al., 2006; CAVALCANTE et al., 2007).

O maracujazeiro amarelo é de elevada sensibilidade aos sais (AYERS; WESTCOT, 1999). Isso significa que a germinação e crescimento inicial podem ser inibidos pelos efeitos nocivos da salinidade do solo ou da água de irrigação.

Essa afirmativa está em coerência com Costa et al. (2005) após constatarem que a irrigação com água salina superior a $1,5 \mathrm{dS} / \mathrm{m}^{-1}$ inibe o processo germinativo, a altura, número de folhas, área foliar e produção de biomassa das raízes e parte aérea das plantas. Informações dessa natureza podem ser úteis aos produtores de mudas em áreas onde a água seja de qualidade restritiva à agricultura.

Entretanto, Cavalcante (2005) após cultivarem o maracujazeiro amarelo no campo, irrigado com águas de condutividade elétrica 3,6 dS $/ \mathrm{m}^{-1}, 1,5$ e 2,0 dS/m $/ \mathrm{m}^{-1}$ e, 3,2 dS $/ \mathrm{m}^{-1}$, constataram que a cultura se comportou, em termos de produtividade, como moderadamente tolerante à salinidade.

Diante destas informações contrastantes conduziu-se este trabalho com o objetivo de estudar os efeitos de diferentes níveis de salinidade da água de irrigação sobre o crescimento inicial do maracujazeiro amarelo.

\section{Materiais e métodos}

A pesquisa foi conduzida em duas etapas, ambas desenvolvidas no Instituto Federal de Educação, Ciência e Tecnologia do Ceará - IFCE, Campus de Sobral, localizado na cidade de Sobral (CE), sob as coordenadas geográficas $03^{\circ} 40^{\prime} \mathrm{S}$ e $40^{\circ} 14^{\prime} \mathrm{W}$. O clima da cidade é tropical quente semiárido com pluviometria média de $854 \mathrm{~mm}$, temperatura média de $30^{\circ} \mathrm{C}$ e a altitude de $70 \mathrm{~m}$ (FUNCEME, 2011).

A primeira etapa da pesquisa, denominada de Experimento I, foi realizada no Laboratório de Análises de Solos e Água para Irrigação e a segunda, denominada Experimento II, realizada em área experimental (casa de vegetação), ambos localizados no IFCE - Campus de Sobral.

O Experimento I consistiu em testes preliminares que possibilitaram a construção de curvas artificiais de salinidade, visando direcionar a aplicação da irrigação com os tratamentos a serem avaliados no segundo experimento. Para encontrar a relação entre a condutividade elétrica da solução (CEs) e os totais de sais dissolvidos, nas proporções desejadas, utilizou-se como referência a equação proposta por Richards (1954), apresentada na equação (1):

$\mathrm{C}=$ CEs.640

Em que: $\mathrm{C}=$ concentração dos sais, $\mathrm{mg} \mathrm{L}^{-1} ; \mathrm{CEs}=$ condutividade elétrica da solução, $\mathrm{dS} / \mathrm{m}^{-1}$;

Foram usadas diferentes soluções de concentrações conhecidas e preparadas a partir da diluição, em balões de $1.000 \mathrm{~mL}$, de um padrão de $6.400 \mathrm{mg} \mathrm{L}^{-1}$, totalizando 21 soluções. A concentração dessas

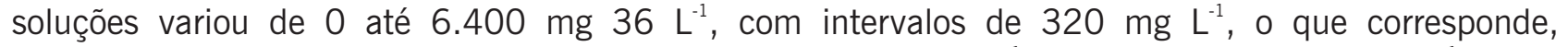
respectivamente, às salinidades teóricas variando de 0 até $10 \mathrm{dS} / \mathrm{m}^{-1}$, com intervalos de $0,5 \mathrm{dS} / \mathrm{m}^{-1}$, tendo como base a equação (1).

O Experimento Il estudou os efeitos desses diferentes níveis de salinidade da água de irrigação $\left(T_{1}=\right.$ testemunha $=0,27 ; T_{2}=1,5 ; T_{3}=2,5 ; T_{4}=3,5$ e $T_{5}=4,5 \mathrm{dS} / \mathrm{m}^{-1}$ ) sobre a germinação das sementes de maracujazeiro amarelo.

Os diferentes níveis de salinidade utilizados na água de irrigação visam simular diversos estágios de salinização, possivelmente encontrados quando detectado o problema pelos agricultores. 
As sementes de maracujazeiro foram semeadas em bandejas, utilizando-se o substrato orgânico comercial Quatro Elementos, com o teor de água próximo à capacidade de campo.

0 delineamento estatístico adotado foi em Delineamento Inteiramente Casualizados (DIC), com cinco tratamentos, níveis de salinidade na água de irrigação $\left(0,27 ; 1,5 ; 2,5 ; 3,5\right.$ e $\left.4,5 \mathrm{dS} / \mathrm{m}^{-1}\right)$, com quatro repetições de 32 sementes cada, sendo caracterizada a unidade experimental.

As variáveis analisadas foram: altura das plântulas (cm): foi realizada com o auxílio de uma régua milimetrada; diâmetro do caule (mm): foi feito com o auxílio de um paquímetro digital da marca Messem; número de folhas definitivas (folhas plantas ${ }^{-1}$ ): foi determinado por meio da contagem semanal das folhas ativas; peso seco aéreo e da raiz (g): foram avaliados no final do experimento, quando as plântulas foram retiradas das bandejas de poliestireno e coletou-se a parte aérea e sistema radicular de cada planta para a obtenção da massa seca. As mesmas foram acondicionadas em sacos de papel tipo Kraft, individualmente, e postas para secar em estufa da marca Heraeus Instruments, modelo T6, a $105 \pm 3{ }^{\circ} \mathrm{C}$, com circulação forçada de ar, pelo período de 24 horas. Passado esse período, as amostras foram retiradas, postas para esfriar e pesadas em balança digital da marca Kern, modelo 770, com precisão de 0,0001 g.

Foram consideradas como emergidas as plântulas que apresentavam os cotilédones totalmente livres, conforme recomendado pela RAS (BRASIL, 2009).

Os resultados foram submetidos à análise de variância pelo teste "F" para diagnosticar os efeitos dos tratamentos, com médias comparadas pelo teste de Tukey, utilizando o software Assistat 7.6 beta (SILVA; AZEVEDO, 2009).

\section{Resultados e discussões}

A partir dos resumos das análises de variância (Tabela 1 ) verifica-se que os sais advindos da água de irrigação exerceram efeitos significativos $(p<0,01)$ sobre a altura das plantas (AP), número de folhas (NF), diâmetro do caule (DC), massa seca da parte aérea (MSPA) e massa seca da raiz (MSR).

Tabela 1: Resumo da análise de variância para altura da planta (AP), número de folhas (NF), diâmetro do caule (DC), massa seca da parte aérea (MSPA) e massa seca da raiz (MSR) do maracujazeiro amarelo submetido a diferentes níveis de salinidade da água de irrigação. Sobral, CE, IFCE - Campus de Sobral, 2013.

\begin{tabular}{cccrr}
\hline Variáveis & QM tratamento & QM resíduo & $\mathrm{F}$ & $\mathrm{CV}(\%)$ \\
\hline AP $(\mathrm{cm})$ & 10,16 & 0,20 & $49,62^{* *}$ & 10,14 \\
NF $\left(\mathrm{f}\right.$ planta $\left.{ }^{-1}\right)$ & 2,19 & 0,036 & $59,51^{* *}$ & 8,75 \\
DC $(\mathrm{mm})$ & 0,075 & 0,0097 & $7,76^{* *}$ & 7,97 \\
MSPA (g) & 1,96 & 0,079 & $24,76^{* *}$ & 40,16 \\
MSR (g) & 0,14 & 0,0023 & $63,28^{* *}$ & 28,96 \\
\hline
\end{tabular}

** significativo ao nível de $1 \%$ de probabilidade $(p<0,01)$

Fonte: ASSISTAT

\section{Altura das plantas e número de folhas}

O incremento da salinidade da água de irrigação provocou uma redução na altura das plantas de maracujazeiro. Plantas irrigadas com água de CEa (condutividade elétrica da água de irrigação) de 0,27 $\mathrm{dS} / \mathrm{m}^{-1}$ obtiveram maior altura. Observa-se que a AP estimada para o menor nível salino de $0,27 \mathrm{dS} / \mathrm{m}^{-1}$ foi de $7,05 \mathrm{~cm}$, enquanto, que para o maior nível foi de $3,07 \mathrm{~cm}$, correspondendo a uma queda estimada de $3,98 \mathrm{~cm}$ na AP. A partir do T1 já houve efeito significativo dos sais advindos da água de irrigação na AP de maracujazeiro amarelo. Para cada incremento unitário de CEa na água de irrigação houve uma redução na 
AP de $2,35,0,52,0,90$ e 0,21 cm, respectivamente entre o T1 e T2, T2 e T3, T3 e T4 e o T4 e T5 (Figura $1 \mathrm{~A})$.
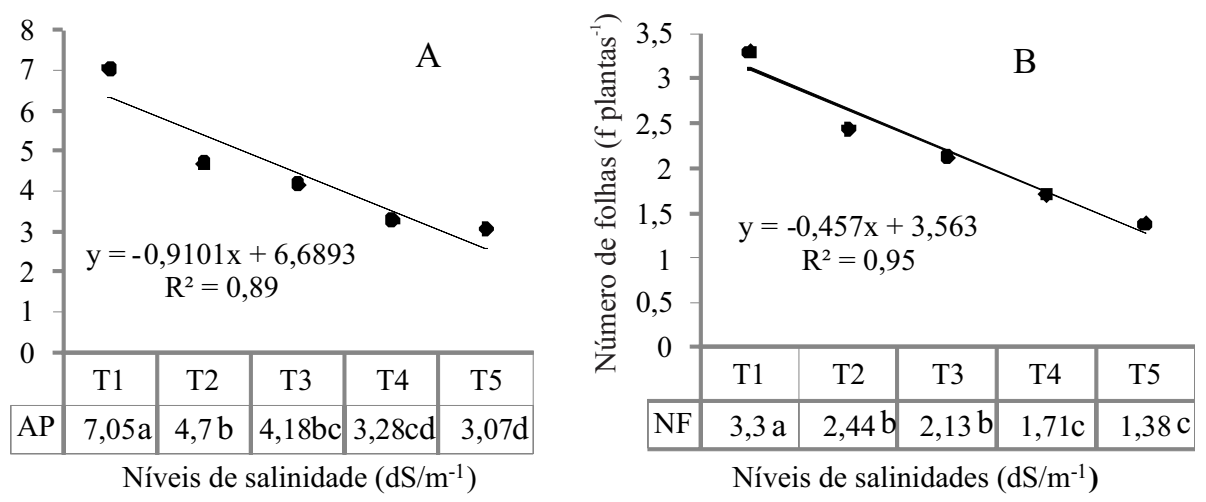

Figura 1: Regressão linear da altura das plantas (AP) e do número de folhas (NF) do maracujazeiro amarelo submetido a cinco níveis de água salina $\left(0,27 ; 1,5 ; 2,5 ; 3,5\right.$ e $\left.4,5 \mathrm{dS} / \mathrm{m}^{-1}\right)$.

As médias seguidas pela mesma letra não diferem estatisticamente entre si, pelo teste de Tukey $(p \leq 0,05)$.

Fonte: Elaboração dos autores.

Nery et al. (2009) trabalhando com o pinhão-manso, também verificaram redução da AP em função do aumento da CEa, indicando que aos 58 DAS (dias após a semeadura) houve decréscimo de 8,6\% na AP quando submeteram-se as plantas à salinidade da água de $3,0 \mathrm{dS} / \mathrm{m}^{-1}$ em relação às plantas cultivadas sob salinidade de 0,6 dS $/ \mathrm{m}^{-1}$. Em pesquisa com nim, Freire et al.(2010) constaram uma redução de $20 \%$ na sua altura a medida que a salinidade do solo aumentou. Costa et al. (2005) verificaram decréscimos relativos na AP de maracujazeiro amarelo de $43,35 \%$ aos 27 DAS.

Para Dias et al. (2006) em um trabalho realizado com salinidade na cultura do melão, os efeitos da salinidade sobre a altura média das plantas foram mais severos durante o desenvolvimento inicial do que no início da frutificação.

Esses decréscimos concordam com Maas e Hoffmam (1977), ao relatarem que com o aumento da concentração salina da solução do solo acima do limite tolerável pelas culturas diminui progressivamente o seu percentual de crescimento.

Com relação ao número de folhas verificou-se comportamento linear decrescente com decréscimos

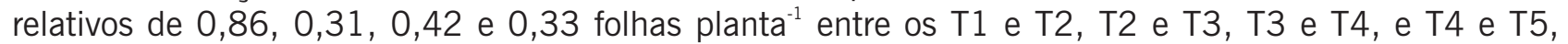
respectivamente. Já comparando o maior e menor nível de salinidade, a redução foi de 1,92 folhas planta ${ }^{-1}$. Os sais exerceram efeitos negativos significativos no NF já a partir do T1, assim como para a AP (Figura 1B).

Trabalhos realizados com outras culturas também demonstram o efeito negativo da salinidade sobre o número de folhas. Silva et al. (2008) verificaram decréscimos linear no NF de 7,5\% por incremento unitário da CEa aos 80 DAS e aos 100 DAS as plantas submetidas a CEa de $6,7 \mathrm{dS} / \mathrm{m}^{-1}$ tiveram redução no $\mathrm{NF}$ de $72,1 \%$ em comparação as irrigadas com água de $0,7 \mathrm{dS} / \mathrm{m}^{-1}$. Costa et al. (2005) encontraram redução de $86,23 \%$ no NF de plantas de maracujazeiro amarelo aos 27 DAS.

Em condições de estresse salino é comum ocorrerem alterações morfológicas e anatômicas nas plantas, que refletem na redução da transpiração como alternativa para manter a baixa absorção de água salina; uma dessas adaptações é a redução do número de folhas (SILVA et al., 2012a).

\section{Diâmetro do caule e massa seca da parte aérea}

O diâmetro do caule das plantas de maracujazeiro amarelo sofreu influência significativa $(p<0,01)$ dos níveis de salinidade na água de irrigação (Tabela 1), apresentando um decréscimo linear em decorrência do aumento da CEa. A queda estimada no DC foi de $0,37 \mathrm{~mm}$ entre 0,27 e 4,5 dS/ $/ \mathrm{m}^{-1}$ da água de irrigação. As plântulas do T1 apresentaram valores de DC iguais estatisticamente aos demais 
tratamentos, com exceção do T5. Já os valores de DC das plântulas do T5 igualaram-se estatisticamente aos T3 e T4 (Figura 2A).

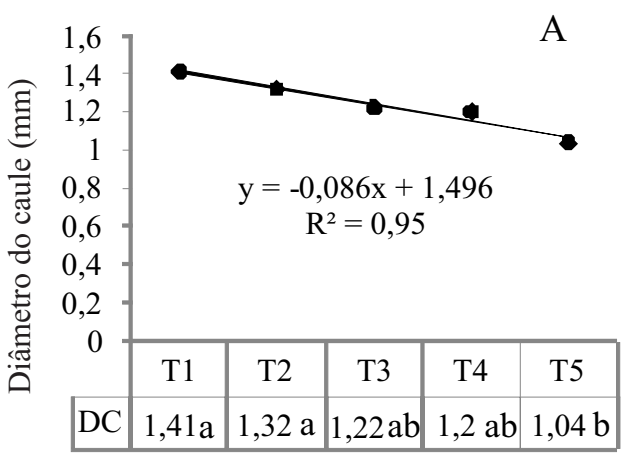

Níveis de salinidade $\left(\mathrm{dS} / \mathrm{m}^{-1}\right)$

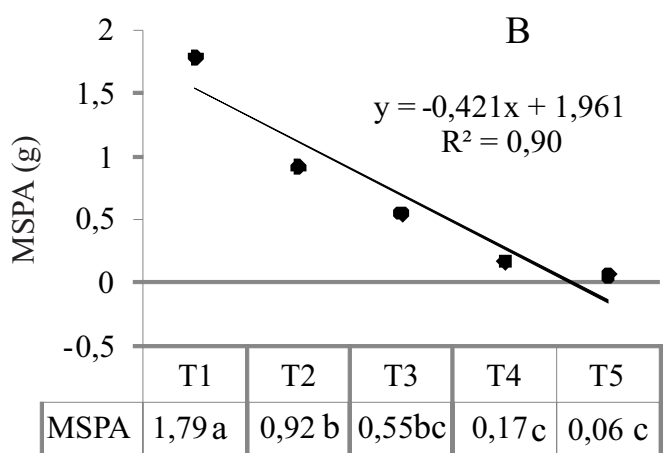

Níveis de salinidade $\left(\mathrm{dS} / \mathrm{m}^{-1}\right)$

Figura 2: Regressão linear do diâmetro do caule (DC) e massa seca da parte aérea (MSPA) do maracujazeiro amarelo submetido a cinco níveis de água salina $\left(0,27 ; 1,5 ; 2,5 ; 3.5\right.$ e $\left.4,5 \mathrm{dS} / \mathrm{m}^{-1}\right)$.

As médias seguidas pela mesma letra não diferem estatisticamente entre si, pelo teste de Tukey $(p \leq 0,05)$.

Fonte: elaboração dos autores.

Reduções no diâmetro do caule causado pelo estresse salino também foram registrados por Costa et al. (2005) e Sousa (2006) no maracujazeiro amarelo. Cavalcanti et al (2005) encontrou um declínio de $0,2 \mathrm{~mm}(1,45 \%)$ no diâmetro do caule, por aumento unitário da CEa. Gurgel et al. (2003) verificaram redução linear de 11,01 e 7,64\% no diâmetro do caule, por incremento unitário da salinidade aos 50 e $90 \mathrm{DAE}$, respectivamente.

A inibição do crescimento do diâmetro do caule possivelmente pode ser provocada pelos efeitos tóxicos dos sais absorvidos pelas plantas principalmente $\mathrm{Na}$ e $\mathrm{Cl}$ nas células e a redução do potencial total da água provocado pelo aumento da concentração salina, ou seja, efeitos diretos e indiretos (MARÇAL, 2011).

Com relação a massa seca da parte aérea, constatou-se redução linear decrescente para esta variável. As reduções corresponderam 0,87; 0,37; 0,38 e 0,11 g entre os T1 e T2, T2 e T3, T3 e T4 e T4 e T5. A MSPA máxima foi de $1,79 \mathrm{~g}$ obtida para as plantas irrigadas com água de $0,27 \mathrm{dS} / \mathrm{m}^{-1}$, enquanto que a MSPA mínima foi de 0,06 g encontrada para as plantas irrigadas com água de 4,5 $\mathrm{dS} / \mathrm{m}^{-1}$. Isto representa uma redução de $1,73 \mathrm{~g}$ entre o maior e menor níveis de salinidade estudados. Assim como para a AP e NF, a MSPA sofreu influência significativa do estresse salino já a partir do T1 (Figura 2B).

Em pinhão-manso, Silva et al. (2012b) constataram um decréscimo linear estimado da MSPA de $13,81 \%$, correspondendo a 2,85 g para cada aumento unitário de CEa. Entre o maior e o menor nível salino estudado, a redução de 11,42 g, o que corresponde a 55,33 \%. Esta redução significativa pode ser resultante da queda na disponibilidade de água dos tecidos vivos, em consequência da elevação dos níveis de CEa (SILVA et al., 2012b).

\section{Massa seca da raiz}

A massa seca da raiz (MSR) das plantas de maracujazeiro decresceu linearmente com o aumento crescente da concentração de sais da água de irrigação. As reduções foram de 0,$35 ; 0,04 ; 0,07$ e $0,02 \mathrm{~g}$, entre os T1 e T2, T2 e T3, T3 e T4 e T4 e T5. Enquanto a testemunha $\left(0,27 \mathrm{dS} / \mathrm{m}^{-1}\right)$ produziu em média $0,50 \mathrm{~g}$ de massa seca, o nível mais alto de salinidade $\left(4,5 \mathrm{dS} / \mathrm{m}^{-1}\right)$ produziu em média $0,020 \mathrm{~g}$. Isto corresponde a uma redução de $0,48 \mathrm{~g}$ na massa seca, comparando os maiores e menores níveis de 
salinidade. 0 estresse salino provocou reduções significativas na MSR já a partir do T1, assim como constatado também para a AP, NF e MSPA. (Figura 3).

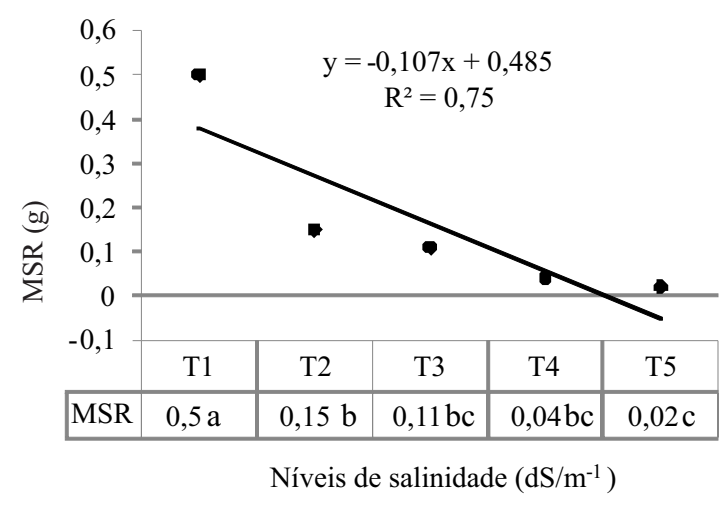

Figura 3: Regressão linear da massa seca da raiz (MSR) do maracujazeiro amarelo submetido a cinco níveis de água salina $\left(0,27 ; 1,5 ; 2,5 ; 3.5\right.$ e $\left.4,5 \mathrm{dS} / \mathrm{m}^{-1}\right)$.

As médias seguidas pela mesma letra não diferem estatisticamente entre si, pelo teste de Tukey $(p \leq 0,05)$.

Fonte: elaboração dos autores

Resultados semelhantes foram encontrados por Miguel et al. (1998), Costa et al. (2005) e Sousa et al. (2006), após constatarem que a irrigação com água salina superior a 1,5 dS/m-1 reduziu a massa seca da raiz no maracujazeiro amarelo.

Para Gurgel et al. (2003), o fato das sementes serem pequenas e portanto, com poucas reservas, utilizam-nas, inicialmente, no crescimento da parte aérea para garantir melhores condições de fotossíntese passando, em seguida, a incrementar a massa radicular, visando acelerar a absorção de água devido ao baixo potencial osmótico, uma vez que as raízes foram menos afetadas com maior tempo de avaliação.

\section{Conclusões}

O maracujazeiro amarelo apresentou elevada sensibilidade aos sais, sendo que com exceção do diâmetro do caule, as demais variáveis avaliadas foram afetadas de maneira significativa pelo estresse salino a partir de $1,5 \mathrm{dS} / \mathrm{m}^{-1}$.

\section{Effect of salinity on initial growth of yellow passion fruit (Passiflora edulis Sims. f. flavicarpa DEG.)}

\section{Abstract}

The objective of this trial was to evaluate the effect of five salinity levels of irrigation water $\left(\mathrm{T}_{1}=\right.$ control $=0.27 ; T_{2}=1.5 ; T_{3}=2.5 ; T_{4}=3.5$ and $T_{5}=4.5 \mathrm{dS} / \mathrm{m}^{-1}$ ), on the initial growth of yellow passion fruit. The work was conducted under laboratory and field (greenhouse) at the Federal Institute of Education, Science and Technology of Ceará-Sobral Campus. The statistical design was a completely randomized design (CRD) with four replications, placing 32 seeds per experimental unit. The variables analyzed were: plant height $(\mathrm{PH})$, number of leaves $(\mathrm{NL})$, stem diameter (DC), dry mass (SDM) androot dry mass (RDM). The yellow passion fruit showed high sensitivity to salts, and with the exception of stem diameter, the other variables were significantly affected by salt stress from $1.5 \mathrm{dS} / \mathrm{m}^{-1}$.

Keywords: Agriculture. Water quality. Salinity stress. 


\section{Referências Bibliográficas}

AYERS, R. S.; WESTCOT, D. W. A qualidade da água na agricultura. Campina Grande: Universidade Federal da Paraíba, 1999. 153p. (Estudos FAO: Irrigação e Drenagem, 29, revisado 1).

BERNSTEIN, L. Salt tolerance of plants. Information Bulletin, n. 283, 23 p., Washington, 1964. (United States Department of Agriculture.)

BETHKE, P. C.; DREW, M.C. Somatal and non-stomatal components to inhibition of photosynthesis in leaves of Capsicum annum during progressive exposure to $\mathrm{NaCl}$ salinity. PlantPhysiol, v.99, n. 12, p.219226, 1992.

BRASIL. Ministério da Agricultura Pecuária e Abastecimento (MAPA). Secretaria de Defesa Agropecuária. Regras para análise de sementes. Brasília: MAPA/ACS, 2009. 395p.

CAVALCANTE, L. F.; et al. Germinação e o crescimento inicial de mudas de goiabeira sob irrigação com água salina Revista Brasileira de Engenharia Agrícola e Ambiental, Campina Grande (PB), 2005, v. 9, n. 4, p. 515- 519.

CAVALCANTE, L. F.; et al. Influência da água salina e matéria orgânica no desempenho do maracujazeiro -amarelo e na salinidade do solo. Irriga, Botucatu (SP), 2007, v. 12, n. 4, p. 505-518.

COSTA, E. da C.; et al. Crescimento inicial do maracujazeiro amarelo sob diferentes tipos e níveis de salinidade da água de irrigação. Revista Brasileira de Engenharia Agrícola e Ambiental, Campina Grande (PB), 2005, v. 9, p. 242-247, (Suplemento).

DIAS, N. da S.; et al. Salinidade e manejo da fertirrigação em ambiente protegido. I: efeitos sobre o crescimento de meloeiro Irriga, Botucatu (SP), 2006, v. 11, n. 2, p. 208-218.

FAO. Global network on integrated soil management for sustainable use of salt-affected soils. 2000a. Disponível em: <http:// www.fao.org/ag/AGL/agll/spush/intro.htm> . Acesso em: 10 maio 2002.

FLOWER, T. J.; HAJIBAGHERI, M. A.; CHIPSON, N. J. W. The mechanism of salt tolelance in halophytes. Annual Review of Plant Physiology, Palo Alto, 1986, v.28, p.89-121.

FREIRE, A. L. de O; ; et al. Crescimento e nutrição mineral do nim (Azadirachta indica A. Juss.) e cinamomo (MeliaazedarachLinn.) submetidos à salinidade. Revista Ciência Florestal, Santa Maria (PR), 2010, v.20, n. 2, p.207-215.

FUNCEME. Disponível em: http://www.funceme.br/index.php/areas. Acesso em: 14 de set. de 2011.

GHEYI, H. R.; FAGERIA, N. K. Efeito dos sais sobre as plantas. In: Manejo e controle da salinidade na agricultura irrigada. Campina Grande, (PB): UFPB, 1997.p.125-131.

GURGEL, M. T.; et al. Estresse salino na germinação e formação de porta-enxerto de Ac roleira. Revista Brasileira de Engenharia Agrícola e Ambiental, Campina Grande (PB), 2003, v. 7, n. 1, p. 31-36.

MAAS, E.V.; HOFFMAN, G.J. Crop salt tolerance: current assessment. Journal of the Irrigation and Drainage Division, 1977, v. 103, n. 2, p. 115-134.

MARÇAL, J.A Crescimento inicial do pinhão-manso (JatrophacurcasL.) sob irrigação com águas salinas em solo com matéria orgânica. 2011, 80 f. Dissertação. (Mestrado em Agronomia: Solos e Nutrição de Plantas), Universidade Federal da Paraíba, Areia, 2011. 
NERY, A. R.; et al. Crescimento do pinhão-manso irrigado com águas salinas em ambiente protegido. Revista Brasileira de Engenharia Agrícola e Ambiental, Campina Grande (PB), 2009,v. 13, n. 5, p. 551558.

O'LEARY, J.W. High humidity overcomes lethal levels of salinity in hydroponical Grown salt-sensitive plants. Plant and Soil, Dordrecht, 1971, v. 42, p.717-721, 1971.

RICHARDS, L. A. Diagnosis and improvement of saline and alkali soils. Washington: United States Salinity Laboratory, 1954. 160p.

SILVA, F. A. S.; AZEVEDO, C. A. V. Principal components Analysis in the Software Assistat- Statistical Attendance.In: WORLD CONGRESS ON COMPUTERS IN AGRICULTURE, 7, 2009, Anais... Reno (NVUSA): American Society of Agricultural and Biological Engineers, 2009. p. 432.

SILVA, M. O.; et al. Crescimento de meloeiro e acúmulo de nutrientes na planta sob irrigação com águas salinas. Revista Brasileira de Engenharia Agrícola e Ambiental, Campina Grande (PB), 2008, v. 12, n. 6 , p. 593-605.

SILVA, J. L de A.; et al. Desenvolvimento inicial do girassol submetido a diferentes níveis de salinidade em dois tipos de solo. Revista Verde, Mossoró (RN), 2012a, v. 7, n. 3, p. 124-131.

SILVA, E. M.; et al. Emergência e crescimento inicial do pinhão-manso (Jatrophacurcas L.) cultivado sob diferentes níveis de salinidade da água de irrigação. Revista Verde, Mossoró (RN), 2012b, v. 7, n. 4, p. 4450 .

WILLADINO, L. G.; CAMARA, T. R. Origen y naturaleza de los ambientes salinos. In: REIGOSA, M. J; PEDROL, N.; SANCHES, A. (Orgs.). La Ecofisologia Vegetal, Madrid, p.303-330. 2004. 